\title{
Faktor-Faktor yang Berhubungan dengan Kadar Hemoglobin pada Siswa SMP
}

\author{
Aisyah1 \\ ${ }^{1}$ Akademi Kebidanan Pelita Persada, Jl Permata No 11, Tawakal, Tomang, Jakarta Barat,
}

\begin{tabular}{|c|c|}
\hline ARTICLE INFORMATION & A B S T R A K \\
\hline $\begin{array}{l}\text { Article Trace } \\
\text { Submission: Mei 02, } 2018 \\
\text { Final Revision: July } 21,2018 \\
\text { Available online: October 20, } 2018\end{array}$ & $\begin{array}{l}\text { Penelitian ini bertujuan untuk mengetahui faktor }- \text { faktor yang } \\
\text { berhubungan dengan kadar hemoglobin pada siswa SMP B di Bekasi } \\
\text { tahun 2015. Apakah ada hubungan antara faktor umur, jenis kelamin, } \\
\text { sarapan pagi, konsumsi tablet tambah darah, merokok, pengetahuan }\end{array}$ \\
\hline $\begin{array}{l}\text { Kata kunci: } \\
\text { Hemoglobin, siswa SMP, cross sectional } \\
\text { KeyWord: } \\
\text { Hemoglobin, students, cross sectional } \\
\text { Contact: } \\
\text { Aisyah_keb@gmail.com }\end{array}$ & $\begin{array}{l}\text { tentang anemia, pendidikan ibu, status pekerjaan ibu, pendapatan orang } \\
\text { tua, dan infeksi. Metode yang digunakan adalah metode kuantitatif } \\
\text { dengan menggunakan desain penelitian Cross Sectional. Populasi } \\
\text { penelitian ini adalah seluruh siswa SMP B di bekasi tahun 2015, } \\
\text { sedangkan sampel dalam penelitian ini adalah yang dipilih berdasarkan } \\
\text { kriteria inklusi berjumlah } 171 \text { responden. Pengolahan data menggunakan } \\
\text { chis square dan regresi logistik ganda. Hasil penelitian ini didapatkan } \\
\text { bahwa kadar hemoglobin siswa }<12 \mathrm{gr} / 100 \mathrm{ml} \text { pada perempuan, dan } \\
13 \mathrm{gr} / 100 \mathrm{ml} \text { pada laki-laki sebesar } 16,5 \% \text {, dan analisis bivariat } \\
\text { menunjukkan terdapat hubungan yang bermakna pada konsumsi tablet } \\
\text { tambah darah }(\mathrm{P}=0,001) \text {, Pengetahuan tentang anemia }(\mathrm{P}=0,001) \text {, } \\
\text { pendidikan ibu siswa }(\mathrm{P}=0,009) \text {, pendapatan orang tua }(\mathrm{P}=0,034) \text { dan } \\
\text { Infeksi ( } \mathrm{P}=0,040) \text {. Hasil analisis multivariat menunjukkan bahwa } \\
\text { variabel yang paling dominan berhubungan adalah konsumsi tablet } \\
\text { tambah darah }(\mathrm{OR}=0,018 \text { dan } \mathrm{P}=0,001) \text { dan pengetahuan remaja } \\
\text { tentang anemia }(7,253 \text { dan p-value } 0,001) \text {. }\end{array}$ \\
\hline
\end{tabular}

\begin{abstract}
A B S T R A C T
This research intent on known factors that associated with hemoglobin rate in junior high school student at bekasi whether there is associated beetwen age, gender, breakfast habbit, ferosus tablet consuption, smoking cigarettes, knowladge about anemia, maternal education, job status, parents income and infection related with hemoglobin rate. This research used Quantitative methode with cross sectional design. Research population are students in SMP B at Bekasi year of 2015, and total sample of this research choosen by the inclusion criteria are 171 respondents Analyzis date use chisquare and multiple logistic regression. This research shows that haemoglobin rate $<12 \mathrm{gr} / 100 \mathrm{ml}$ in female student and $<13 \mathrm{gr} / 100 \mathrm{ml}$ in male student are $16,5 \%$. Bivariate analysis shows that there are significant difference in ferrosus tablet comsuption ( $\mathrm{P}=0,001)$, knowledge rate about anemia $(\mathrm{P}=0,001)$, maternal education $(\mathrm{P}=0,009)$, Parents income $(\mathrm{P}=0,034)$, and infection status $(\mathrm{P}=0,040)$. Multivariate analysis shows that the most dominan factor are ferrosus tablet consuption $(\mathrm{OR}=0,018$ dan $\mathrm{P}=0,001)$ and knowladge rate about anemia (7,253 dan p-value 0,001$)$.
\end{abstract}




\section{LATAR BELAKANG}

Anemia karena defisiensi zat besi merupakan kelainan gizi yang paling sering ditemukan di dunia, sebanyak 4-5 milyar penduduk dunia, atau $66-80 \%$ dari populasi penduduk dunia, mungkin mengalami defisiensi zat besi; 2 milyar penduduk dunia, mengalami anemia, terutama karena defisiensi zat besi, dan di negara berkembang, keadaan ini semakin diperparah oleh penyakit malaria serta infeksi cacing.

Di negara berkembang masih terjadi peningkatan kasus anemia zat gizi besi (Fe). Akibat anemia Fe adalah penurunan daya kognitif/intelektual, prestasi belajar, dan rendahnya kapasitas/produktivitas kerja. Pada tahun 2003 WHO memprediksi sekitar $27 \%$ remaja puteri di negara berkembang menderita anemia. Studi Indian Council of Medial Research (ICMR) menyatakan tingginya prevalensi anemia di India (55\%), Nepal (42\%), Kamerun (32\%), dan Guatemala (48\%). Pada penelitian yang dilakukan oleh Permaesih, D \& Herman, S. (2005) didapatkan prevalensi anemia pada remaja sebesar yaitu $75 \%$. Berdasarkan hasil penelitian Annas (2011) di MTs Al Asror Kecamatan Gunungpati Semarang didapatkan prevalensi anemia pada remaja sebesar $81,0 \%$.

Anemia ditandai dengan rendahnya konsentrasi hemoglobin $(\mathrm{Hb})$, atau hematokrit nilai ambang batas (referensi) yang disebabkan oleh rendahnya produksi sel darah merah (eritrisit) dan $\mathrm{Hb}$, meningkatnya kerusakan eritrosit (hemolis), atau kehilangan darah yang berlebihan.

Anemia adalah suatu keadaan kadar hemoglobin dalam darah lebih rendah dari nilai normal. Nilai batas ambang anemia untuk umur 5-11 tahun $<$ $11,5 \mathrm{~g} / \mathrm{L}, 11-14$ tahun $<2,0 \mathrm{~g} / \mathrm{L}$, remaja diatas 15 tahun untuk anak perempuan $<12,0 \mathrm{~g} / \mathrm{L}$ dan anak laki-laki $<13,0 \mathrm{~g} / \mathrm{L}$.

Defisiensi zat besi dan anemia dapat menurunkan kapasitas kerja individual dan keseluruhan populasi dengan membawa akibat ekonomi yang serius dan menjadi penghalang bagi perkembangan nasional. Sebaliknya, penanganan keadaan tersebut dapat menaikan tingkat produktifitas nasional sebesar $20 \%$.

Terjadinya anemia disebabkan oleh beberapa faktor. Penyebab utama dapat dikategorikan dengan kategori rendah, kekurangan, atau produksi sel darah merah yang abnormal; pemecahan sel darah merah yang berlebihan; dan hilangnya sel darah merah secara berlebihan. Penyebab yang berkaitan dengan kurang gizi, dihubungkan pada asupan makanan, kualitas makanan, sanitasi dan perilaku kesehatan; kondisi lingkungan sekitar; akses kepada pelayanan kesehatan; dan kemiskinan. Penyebab yang penting juga disesuaikan dengan daerah .

Berdasarkan hasil studi pendahuluan di SMP B di Bekasi, didapatkan hasil pemeriksaan kadar hemoglobin pada sepuluh siswa dengan hasil. Sebanyak tujuh siswa yang terdiri dari 5 siswa perempuan memiliki kadar hemoglobin $\leq 12$ gr/dl dan dua siswa laki-laki memiliki kadar hemoglobin $\leq 13 \mathrm{gr} / \mathrm{dl}$, serta sejumlah satu siswa perempuan memiliki kadar hemoglobin 12.0 $\mathrm{gr} / \mathrm{dl}$ dua siswa laki-laki memiliki kadar hemoglobin $13.0 \mathrm{gr} / \mathrm{dl}$. Berdasarkan hasil wawancara, rata-rata dari sepuluh siswa berasal dari keluarga dengan status sosial ekonomi menengah kebawah, dengan status pekerjaan orang tua sebagai buruh pabrik.

\section{METODE}

Metode yang digunakan adalah metode kuantitatif dengan menggunakan desain penelitian Cross Sectional. Populasi penelitian ini adalah seluruh siswa SMP B di bekasi tahun 2015, sedangkan sampel dalam penelitian ini adalah yang dipilih berdasarkan kriteria inklusi berjumlah 171 responden. Pengolahan data menggunakan chis square dan regresi logistik ganda.

\section{HASIL DAN PEMBAHASAN}

Gambaran Kadar Hemoglobin Pada Siswa SMP B di Bekasi Tahun 2015 Pada penelitian ini didapatkan hasil kadar hemoglobin siswa dengan status anemia sejumlah $61,5 \%$ siswa yang terdiri dari $65,4 \%$ perempuan dan $55,2 \%$ lakilaki, dengan total sampel penelitian 171 siswa 
SMP B di Bekasi tahun 2015. Penelitian ini menggambarkan bahwa masih tingginya anemia pada remaja di sekolah SMP B. Fatmah (2010) mengatakan di negara berkembang masih terjadi peningkatan kasus anemia zat gizi besi $(\mathrm{Fe})$. Akibat anemia $\mathrm{Fe}$ adalah penurunan daya kognitif/intelektual, prestasi belajar, dan rendahnya kapasitas/produktivitas kerja. Pada tahun 2003 WHO memprediksi sekitar 27\% remaja puteri di negara berkembang menderita anemia. Studi Indian Council of Medial Research (ICMR) menyatakan tingginya prevalensi anemia di India (55\%), Nepal (42\%), Kamerun (32\%), dan Guatemala (48\%). Sebagian besar remaja puteri dan putera menderita defisiensi $\mathrm{Fe}$, dan anemia $\mathrm{Fe}$ karena meningkatnya kebutuhan $\mathrm{Fe}$ selama proses pertumbuhan. Penyakit infeksi seperti malaria, schis-tosomiasis, dan kecacingan mempengaruhi absorpsi dan meningkatnya kehilangan $\mathrm{Fe}$ dari dalam tubuh.

Faktor-faktor yang Mempengaruhi Kadar Hemoglobin Pada Siswa SMP B di Bekasi Tahun 2015.

\section{Tabel 1. Variabel kandidat multivariat hasil analisis regresi binary yang berhubungan dengan kadar hemoglobin pada siswa SMP B di Bekasi Tahun 2015}

\begin{tabular}{|c|c|c|c|c|}
\hline No & Variabel & OR & $95 \% \mathrm{Cl}$ & PValue \\
\hline 1 & $\begin{array}{l}\text { Konsumsi } \\
\text { Tablet } \\
\text { Tambah } \\
\text { Darah }\end{array}$ & 0,018 & $0,002-0,132$ & 0,001 \\
\hline 2 & $\begin{array}{l}\text { Pengetahuan } \\
\text { Tentang } \\
\text { Anemia }\end{array}$ & 7,253 & $2,557-20,570$ & 0,001 \\
\hline 3 & Merokok & 1,556 & $0,720-3,365$ & 0,261 \\
\hline 4 & $\begin{array}{l}\text { Pendidikan } \\
\text { Ibu }\end{array}$ & 0,353 & $0,161-0,772$ & 0,009 \\
\hline 5 & $\begin{array}{l}\text { Status } \\
\text { Pekerjaan } \\
\text { lbu }\end{array}$ & 0,296 & $0,073-1,197$ & 0,088 \\
\hline 6 & $\begin{array}{l}\text { Pendapatan } \\
\text { Orang Tua }\end{array}$ & 2,465 & $1,069-5,684$ & 0,034 \\
\hline 7 & Infeksi & 2,351 & $1,038-5,325$ & 0,040 \\
\hline
\end{tabular}

Berdasarkan hasil perhitungan siswa berumur $\geq$ 14 tahun $(55,6 \%)$ sebanyak kemudian diikuti oleh siswa yang berumur $<14$ tahun sebesar 76 $(44,4 \%)$. Berdasarkan hasil analisis hubungan antara umur siswa dengan kadar hemoglobin diperoleh OR $(95 \% \mathrm{CI}) 1,26$ adalah $(0,67-2,35)$
$P$ value $=0,562$ berarti siswa yang berumur $\geq 14$ tahun berisiko 1,26 kali dengan anemia dengan kadar hb untuk Perempuan HB $<12$ gr/100 ml \& Laki-laki $<13 \mathrm{gr} / 100 \mathrm{ml}$ dibandingkan siswa yang berumur $<14$ tahun. maka dapat di simpulkan bahwa umur siswa tidak berhubungan dengan kejadian anemia pada remaja.

Berdasarkan hasil analisis hubungan antara jenis kelamin siswa dengan kadar hemoglobin diperoleh OR $(95 \% \mathrm{CI}) 1,5$ adalah $(0,8-2,9) \mathrm{P}$ value $=0,241$ berarti siswa yang berjenis kelamin perempuan berisiko 1,5 kali dengan anemia kadar hb untuk Perempuan $\mathrm{HB}<12$ $\mathrm{gr} / 100 \mathrm{ml}$ dibandingkan siswa laki-laki. maka dapat di simpulkan bahwa jenis kelamin siswa tidak berhubungan dengan kejadian anemia pada remaja.

Berdasarkan hasil analisis hubungan antara siswa yang sarapan pagi dengan kadar hemoglobin diperoleh OR $(95 \% \mathrm{CI})$ adalah 1,1 $(0,6-2,0) \mathrm{P}$ value $=0,884$ berarti siswa yang tidak sarapan pagi berisiko 0,884 kali mengalami anemia dengan kadar hb untuk Perempuan $\mathrm{HB}<$ $12 \mathrm{gr} / 100 \mathrm{ml} \&$ Laki-laki $<13 \mathrm{gr} / 100 \mathrm{ml}$ dibandingkan siswa yang sarapan pagi. maka dapat di simpulkan bahwa siswa yang sarapan pagi tidak berhubungan dengan kejadian anemia pada remaja.

Berdasarkan hasil perhitungan Siswa yang mengkonsumsi tablet tambah darah (TTD) dengan OR 0,021 dan $\mathrm{p}=0,001$ artinya siswa yang tidak mengkonsumsi tablet tambah darah (TTD) memiliki risiko 0,021 mengalami anemia dengan kadar hemoglobin untuk Perempuan HB $<12 \mathrm{gr} / 100 \mathrm{ml} \&$ Laki-laki $<13 \mathrm{gr} / 100 \mathrm{ml}$, dibandingkan dengan siswa yang mengkonsumsi tablet tambah darah (TTD). Didapatkan juga siswa yang tidak mengkonsumsi tablet tambah darah mempunyai kontribusi 2,66 - 21,56 kali terhadap Anemia dengan kadar hemoglobin untuk Perempuan $\mathrm{Hb}<12 \mathrm{gr} / 100 \mathrm{ml} \&$ Laki-laki $\mathrm{Hb}<13 \mathrm{gr} / 100 \mathrm{ml}$ dengan tingkat kepercayaan 95\%. Maka dapat di simpulkan bahwa siswa yang mengkonsumsi tablet tambah darah (TTD) berhubungan dengan kejadian anemia pada remaja.

Berdasarkan hasil analisis hubungan antara siswa yang merokok dengan kadar hemoglobin diperoleh OR $(95 \% \mathrm{CI})$ adalah $0,6(0,32-1,15) \mathrm{P}$ value $=0,173$ berarti siswa yang merokok 
berisiko 0,173 kali mengalami anemia dengan kadar hb untuk Perempuan HB $<12$ gr/100 $\mathrm{ml} \&$ Laki-laki $<13 \mathrm{gr} / 100 \mathrm{ml}$ dibandingkan siswa yang tidak merokok. maka dapat di simpulkan bahwa siswa yang merokok tidak berhubungan dengan kejadian anemia pada remaja. Dalam pembahasan hasil penelitian yang dilakukan oleh Permaesih (2005) didapatkan proporsi remaja yang merokok sebesar $10 \%$, hal ini menunjukkan bahwa perlu adanya perhatian yang lebih, baik pada orang tua dan guru di sekolah untuk mencegah dampak lanjut yang lebih besar.

Pengetahuan tentang anemia pada siswa dengan OR 7,578 dan $\mathrm{p}=0,001$ artinya siswa yang memiliki pengetahuan yang buruk tentang anemia memiliki risiko 7,578 mengalami anemia dengan kadar hemoglobin untuk Perempuan $\mathrm{Hb}$ $<12 \mathrm{gr} / 100 \mathrm{ml} \&$ Laki-laki $\mathrm{Hb}<13 \mathrm{gr} / 100 \mathrm{ml}$ dibandingkan dengan siswa yang memiliki pengetahuan tentang anemia yang baik. Didapatkan juga siswa yang memiliki pengetahuan tentang anemia yang buruk mempunyai kontribusi 0,003 - 0,151 kali terhadap anemia dengan kadar hemoglobin untuk Perempuan $\mathrm{Hb}<12 \mathrm{gr} / 100 \mathrm{ml} \&$ Laki-laki $\mathrm{Hb}<13 \mathrm{gr} / 100 \mathrm{ml}$ dengan tingkat kepercayaan 95\%. Maka dapat di simpulkan bahwa pengetahuan siswa tentang anemia berhubungan dengan kejadian anemia pada remaja.

Berbeda dengan hasil penelitian yang dilakukan oleh Ida Farida (2006) dan Nahsty, R (2011) tentang hubungan pengetahuan anemia pada remaja dengan kadar hemoglobin, dengan hasil penelitian tidak adanya hubungan antara tingkat pengetahuan anemia pada remaja dengan kadar hemoglobin dengan nilai $\mathrm{P}=0,358$ dan $\mathrm{P}=0,770$.

Pendidikan ibu siswa dengan OR 0,350 dan $\mathrm{p}=0,008$ artinya siswa dengan ibu tamatan SD Tamatan SLTP memiliki risiko 0,350 kali mengalami anemia dengan kadar hemoglobin untuk Perempuan $\mathrm{Hb}<12 \mathrm{gr} / 100 \mathrm{ml} \&$ Laki-laki $\mathrm{Hb}<13 \mathrm{gr} / 100 \mathrm{ml}$ dibandingkan siswa dengan ibu tamatan SLTA - Tamatan PT. Didapatkan juga siswa dengan ibu tamatan SD - Tamatan SLTP mempunyai kontribusi $0,16-0,76$ kali terhadap anemia dengan kadar hemoglobin untuk Perempuan $\mathrm{Hb}<12 \mathrm{gr} / 100 \mathrm{ml} \&$ Laki-laki $\mathrm{Hb}<13 \mathrm{gr} / 100 \mathrm{ml}$ dengan tingkat kepercayaan 95\%. Maka dapat di simpulkan bahwa pendidikan ibu siswa berhubungan dengan kejadian anemia pada remaja.
Status pekerjaan ibu responden dengan OR 0,268 dan $\mathrm{p}=0,065$ artinya mahasiswa dengan status pekerjaan ibu bekerja memiliki risiko 0,268 kali mengalami anemia dengan kadar hemoglobin untuk perempuan $\mathrm{Hb}<12$ gr/100 $\mathrm{ml} \&$ Laki-laki $\mathrm{Hb}<13 \mathrm{gr} / 100 \mathrm{ml}$ dibandingkan siswa dengan status pekerjaan ibu tidak bekerja. Didapatkan juga siswa dengan status pekerjaan ibu bekerja mempunyai kontribusi 0,06 - 1,08 kali terhadap anemia dengan kadar hemoglobin untuk Perempuan $\mathrm{Hb}<12 \mathrm{gr} / 100 \mathrm{ml} \&$ Laki-laki $\mathrm{Hb}<13 \mathrm{gr} / 100 \mathrm{ml}$ dengan tingkat kepercayaan 95\%. Maka dapat di simpulkan bahwa status pekerjaan ibu siswa berhubungan dengan kejadian anemia pada remaja.

Pendapatan orang tua dengan OR 2,32 dan $\mathrm{p}=0,045$ artinya siswa dengan pendapatan orang tua < UMR Kota Bekasi 2.900.000 memiliki resiko 2,32 kali mengalami anemia dengan kadar hemoglobin untuk perempuan $\mathrm{Hb}<12$ $\mathrm{gr} / 100 \mathrm{ml} \&$ Laki-laki $\mathrm{Hb}<13 \mathrm{gr} / 100 \mathrm{ml}$ dibandingkan dengan siswa dengan pendapatan orang tua $\geq$ UMR Kota Bekasi 2.900.000. Didapatkan juga siswa dengan pendapatan orang tua < UMR Kota Bekasi 2.900.000 mempunyai kontribusi 1,019 - 5,29 kali terhadap anemia dengan kadar hemoglobin untuk perempuan $\mathrm{Hb}$ $<12 \mathrm{gr} / 100 \mathrm{ml} \&$ Laki-laki $\mathrm{Hb}<13 \mathrm{gr} / 100 \mathrm{ml}$ dengan tingkat kepercayaan 95\%. Maka dapat di simpulkan bahwa pendapatan orang tua siswa berhubungan dengan kejadian anemia pada remaja.

Berdasarkan hasil analisis hubungan antara penyakit infeksi siswa dengan kadar hemoglobin diperoleh OR $(95 \% \mathrm{CI})$ adalah 2,557 (0,32 $1,26) \quad \mathrm{P}$ value $=0,022$ berarti siswa yang mengalami dalam 1 bulan menderita ISPA/Diare/TBC 0,63 kali dengan anemia dimana kadar hb untuk Perempuan HB $<12$ $\mathrm{gr} / 100 \mathrm{ml} \&$ Laki-laki < $13 \mathrm{gr} / 100 \mathrm{ml}$ dibandingkan siswa yang dalam 1 bulan tidak menderita ISPA/Diare/TBC . maka dapat di simpulkan bahwa infeksi pada siswa berhubungan dengan kejadian anemia pada remaja

\section{KESIMPULAN}

Pada penelitian ini didapatkan hasil kadar hemoglobin siswa dengan status anemia sejumlah $61,4 \%$ siswa yang terdiri dari $65,4 \%$ perempuan dan 55,2\% laki-laki, dengan total 
sampel penelitian 171 siswa SMP B di Bekasi tahun 2015.

Siswa yang tidak mengkonsumsi tablet tambah darah (TTD) memiliki nilai OR 0,021 dan $\mathrm{p}=0,001$ hal ini dapa diartikan bahwa siswa yang tidak mengkonsumsi tablet tambah darah memiliki resiko 0,021 menderita anemia dengan kadar hemoglobin untuk Perempuan $\mathrm{Hb}<12$ $\mathrm{gr} / 100 \mathrm{ml} \&$ Laki-laki $\mathrm{Hb}<13 \mathrm{gr} / 100 \mathrm{ml}$. Didapatkan juga siswa yang tidak mengkonsumsi tablet tambah darah mempunyai kontribusi 2,66 - 21,56 kali terhadap Anemia dengan tingkat kepercayaan 95\%.

Siswa yang memiliki pengetahuan tentang anemia yang buruk mendapatkan nilai OR 7,578 dengan nilai $\mathrm{p}=0,001$ dan mempunyai kontribusi $0,003-0,151$ kali terhadap anemia dengan kadar hemoglobin untuk Perempuan $\mathrm{Hb}$ $<12 \mathrm{gr} / 100 \mathrm{ml} \&$ Laki-laki $\mathrm{Hb}<13 \mathrm{gr} / 100 \mathrm{ml}$ dengan tingkat kepercayaan 95\%.

Pendidikan ibu siswa dengan OR 0,350 dan $\mathrm{p}=0$, siswa dengan ibu tamatan SD - Tamatan SLTP mempunyai kontribusi $0,16-0,76$ kali terhadap anemia dengan kadar hemoglobin untuk Perempuan $\mathrm{Hb}<12 \mathrm{gr} / 100 \mathrm{ml} \&$ Laki-laki $\mathrm{Hb}<$ $13 \mathrm{gr} / 100 \mathrm{ml}$ dengan tingkat kepercayaan 95\%.

Status pekerjaan ibu responden dengan OR 0,268 dan $p=0,065$ siswa dengan status pekerjaan ibu bekerja mempunyai kontribusi 0,06 - 1,08 kali terhadap anemia dengan kadar hemoglobin untuk Perempuan $\mathrm{Hb}<12$ gr/100 $\mathrm{ml} \&$ Laki-laki $\mathrm{Hb}<13 \mathrm{gr} / 100 \mathrm{ml}$ dengan tingkat kepercayaan 95\%.

Pendapatan orang tua dengan OR 2,32 dan $\mathrm{p}=0,045$ siswa dengan pendapatan orang tua $<$ UMR Kota Bekasi 2.900.000 mempunyai kontribusi 1,019 - 5,29 kali terhadap anemia dengan kadar hemoglobin untuk perempuan $\mathrm{Hb}$ $<12 \mathrm{gr} / 100 \mathrm{ml} \&$ Laki-laki $\mathrm{Hb}<13 \mathrm{gr} / 100 \mathrm{ml}$ dengan tingkat kepercayaan $95 \%$.

\section{DAFTAR PUSTAKA}

Ali Khomsan. 2003. Pangan dan Gizi Untuk Kesehatan. Jakarta : Grafindo

Ali Khomsan. 2006. Solusi Makanan Sehat. Jakarta : Grafindo
Almatsier S.2004. Prinsip Dasar 1lmu Gizi. Jakarta: Gramedia Pustaka Utama

Anonim. 2008. Gizi dan Kesehatan Masyarakat/Departemen Gizi dan Kesehatan Masyarakat Fakultas Kesehatan Masyarakat Universitas Indonesia- Ed. 1,- 2,- Jakarta: PT Raja Grafindo Persada.

Arisman, MB. 2004. Gizi Dalam Daur Kehidupan : Buku Ajar Ilmu Gizi.Jakarta: EGC

Astawan, M \& Kasih,L,A. 2008. Khasiat WarnaWarni Makanan. Jakarta: PT Gramedia Pustaka Utama

Berg, A. 1986. Peranan Gizi Dalam Pembangunan Nasional. Rajawali, CV. Jakarta

Fatmah. 2010. Pengalaman Negara Lain dalam Perbaikan Gizi Remaja Sekolah Menengah. Departemen Gizi Kesmas Fakultas Kesehatan Masyarakat Universitas Indonesia, Jakarta

Gibney, Michel J et al. 2009. Gizi Kesehatan Masyarakat . Alih bahasa Andry Hartono et al. Jakarta: EGC

Gino, Suwarni, Suripto, Maryanto dan Sutijan. 1996. Belajar dan Pembelajaran I. Surakarta : UNS Press.

Hallberg, B. Sandstrom and P.J. Agget L. Iron, zinc and other trace elements. In : Human Nutrition and Dietetics. Churchill Livingstone. 1994.

Hardinsyah. 1997. Ekonomi Gizi. Jurusan Gizi Masyarakat dan Sumberdaya

Keluarga. Fakultas Pertanian IPB. Bogor

Harmening, Denise. (2009). Clinical Hematology and Fundamentals of Hemostasis. F.A. Davis. ISBN 978-0803617-322.

Hendra Surya. 2009. Menjadi Manusia Pembelajar. Jakarta: PT Alex Media Komputindo 
Heryanti, Evi, 2009. Hubungan Kebiasaan Makan Cepat Saji (Fast Food Modern), Aktivitas Fisik dan Faktor Lainnya Dengan Status Gizi Mahasiswa Penghuni Asrama UI Depok. Skripsi. FKM UI.

http://www.sangobion.co.id/blood_health/anemi a/what is_anemia. di akses tanggal 10 Juni 2014

http://idai.or.id/public-articles/seputarkesehatan-anak/overview-adolescenthealth-problems-and-services.html di akses tanggal 10 Juni 2014http://gizi.depkes.go.id/wpcontent/uploads/2011/11/LEMBARINFORMASI-NO-2-2011.pdf mengapa sarapan itu penting?

Ida Farida. 2006. Determinan Kejadian Anemia Pada Remaja Putri Di Kecamatan Gebog Kabupaten Kudus tahun 2006. Tesis. UNDIP

Kee, Joyce LeFever. 2002. Buku Saku Pemeriksaan Laboratorium dan Diagnostik dengan Implikasi Keperawatan. Alih bahasa Ester Nurses. Jakarta: EGC

Muscary \& Mary E. 2005. Panduan Belajar Keperawatan Pediatrik. Alih bahasa Alfrina Hany et al. Jakarta: EGC

Nahsty Raptauli, S. 2011. Faktor-Faktor Yang Berhubungan Dengan Status Anemia
Pada Remaja Putri Di Wilayah Kota Depok 2011 (Analisis Data Sekunder Survei Anemia Remaja Putri Dinas Kesehatan Kota Depok Tahun 2011). Skripsi. UI, Jakarta

Nokes, C at al. 1998. The Effects Of Iron Deficiency and Anemia On Mental and Motor Performance, Educational Achievement, and Behaviour in Children: An Annotated Bibliography. United States of America

Nursyahidah, I. 2014. Hubungan Pengetahuan Dan Sikap Tentang Anemia Dengan Status Hemoglobin Pada remaja Putri di SMA Negri 10 Makassar. Skripsi. FKM UNHAS.

Suhardjo. 1989. Sosio Budaya Gizi. IPB Pusat Antar Universitas Pangan dan Gizi. Bogor

Suhardjo. 1996. Berbagai Cara Pendidikan Gizi. Bumi Aksara dan Pusat Antar Universitas Pangan dan Gizi. Institut Pertanian Bogor. Bogor.

Sacher, Ronald A et al. 2004. Tinjauan Klinis Hasil Pemeriksaan, Laboratorium. Alih bahasa Brahm U et al. Jakarta: EGC

Sjahmien Moehji. 2000. Ilmu Gizi dan Penanggulangan Gizi Buruk. Jakarta: Papas Sinar Sinanti

Suhardjo. 1986. Pangan Gizi dan Pertanian. Universitas Indonesia, Jakarta. 